\title{
AMENDMENTS
}

\section{Publisher Correction: China's roadmap for planetary exploration}

Yong Wei, Zhonghua Yao and Weixing Wan

Correction to: Nature Astronomy https://doi.org/10.1038/s41550-018-0456-6, published online 1 May 2018.

In the version of this Comment originally published, a sentence in the seventh paragraph incorrectly stated that plasma analysers on board the Chinese Mars mission orbiter will measure the surface magnetic field. The sentence 'The orbiter will also have plasma analysers on-board for measuring the surface magnetic field along the rover's trajectory' should have read 'The Chinese Mars mission orbiter will also have plasma analysers on-board, and the mission rover will measure the surface magnetic field along its trajectory'. This has now been corrected.

Published online: 5 December 2019

https://doi.org/10.1038/s41550-019-0993-7

๑) Springer Nature Limited 2019 